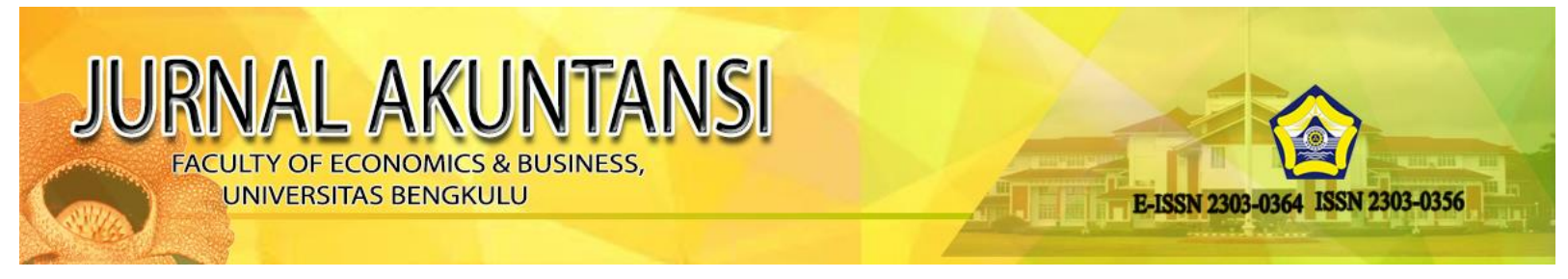

\title{
FAKTOR-FAKTOR YANG MEMPENGARUHI MINAT PENGELOLA KEUANGAN MELAKUKAN TINDAKAN WHISTLE -BLOWING (Studi Kasus Pada Universitas Bengkulu)
}

\section{THE FACTORS FOR INFLUENCING FINANCIAL MANAGER DESIRES TO DO WHISTLE-BLOWING ACTION. (The Case study in Universitas Bengkulu)}

\author{
Dewi Sutrisni ${ }^{1}$ ), Isma Coryanata ${ }^{2}$ ) \\ Universitas Bengkulu, Jl. WR. Supratman,Kandang Limun, Muara Bangkahulu, Bengkulu \\ dsutrisni15@gmail.com ${ }^{\text {}}$ ), ismacoryanata@yahoo.com²)
}

\begin{abstract}
ABSTARACT
This study aims to examine the influence of attitude factors on whistle-blowing, organizational commitment, personal cost, the degree of seriousness of fraud and the pressure of obedience to the interest of financial managers performing whistle-blowing action on the financial manager of Bengkulu University. The data used in this study is the primary data collected through survey method by distributing 106 questionnaires to the financial manager in Bengkulu University units. Questionnaires were made using two different cases resulting in different data processing results in each case. The results showed that in the first case only the attitude toward whistle-blowing that positively affect the interest of financial managers doing whistle-blowing action and 4 other variables have no effect. In the second case, the attitude toward whistle-blowing and the pressure of obedience have a positive effect on the interest of the financial managers perform whistle-blowing action while the organizational commitment variable, personal cost, the seriousness of the fraud does not affect the financial manager's interest in doing the whistle-blowing action. Discussions of the implications of the research results and their limitations have also been made.
\end{abstract}

Key words: whistle-blowing, organizational commitment, personal cost, level of fraud seriousness, pressure of obedience

\begin{abstract}
ABSTRAK
Penelitian ini bertujuan untuk menguji pengaruh faktor sikap terhadap whistle-blowing, komitmen organisasi, personal cost, tingkat keseriusan kecurangan dan tekanan ketaatan terhadap minat pengelola keuangan melakukan tindakan whistle-blowing pada pengelola keuangan Universitas Bengkulu. Data yang digunakan dalam penelitian merupakan data primer yang dikumpulkan melalui metode survei dengan membagikan 106 kuisioner pada pengelola keuangan di unit-unit Universitas Bengkulu. Kuisioner dibuat menggunakan dua kasus yang berbeda sehingga menghasilkan hasil pengolahan data yang berbeda pula pada setiap kasus. Hasil penelitian menunjukkan bahwa pada kasus pertama hanya sikap terhadap whistle-blowing yang berpengaruh positif terhadap minat pengelola keuangan melakukan tindakan whistle-blowing sedabgkan 4 variabel yang lain tidak berpengaruh. Sedangkan pada kasus kedua sikap terhadap whistle-blowing dan tekanan ketaatan berpengaruh positif terhadap minat pengelola keuangan melakukan tindakan whistle-blowing sedangkan variabel komitmen organisasi, personal cost, tingkat keseriusan kecurangan tidak berpengaruh terhadap minat pengelola keuangan melakukan tindakan whistle-blowing . Diskusi terhadap implikasi hasil penelitian dan keterbatasannya juga telah dilakukan.
\end{abstract}

Kata kunci: whistle-blowing, komitmen organisasi, personal cost, tingkat keseriusan kecurangan, tekanan ketaatan 
FAKTOR - FAKTOR YANG MEMPENGARUHI...

Dewi Sutrisni dan Isma Coryanata

\section{PENDAHULUAN}

Korupsi selalu menimbulkan kerugian, untuk itu korupsi harus diberantas. Seberapun kecilnya dana yang dikorupsi sama strategisnya dengan pemberantasan korupsi besar (Diniarti, 2010). Sekecil apapun korupsi jika dibiarkan akan semakin buruk. Di Indonesia kasus-kasus korupsi bukanlah kasus yang mengagetkan, dalam beberapa tahun belakangan ini banyak sekali kasus-kasus korupsi yang terungkap baik dari sektor swasta maupun di sektor pemerintahan kasus ini mendapatkan perhatian yang sangat serius dari pemerintah. Khususnya yang terjadi si sektor publik di Indonesia, kecurangan yang paling sensitif dan menjadi perhatian saat ini adalah korupsi.

Di Indonesia kasus kecurangan yang pernah terbongkar Kasus Bank Century menyeret nama mantan wakil presiden Budiono dan menteri keuangan Sri Mulyani ini cukup menyita perhatian masyarakat, pasalnya kerugian negara ditaksir mencapai 6,7 triliun. Kasus Korupsi Nazarudin Kerugian negara mencapai 1 Triliun (\$600 juta) oleh kasus Nazarudin yang berupa suap di kemenpora, korupsi PLTS, dan beberapa dinas lain. Kasus ini merupakan salah satu kasus korupsi terhebat yang terungkap, karena berkat kerja keras aparat, Nazarudin bisa dihukum atas kasusnya. Pada tahun 2017 ini adalah kasus e-KTP dengan tersangka Ketua DPR RI Setya Novanto, yang merugikan keuangan negara $\mathrm{Rp} 2,3$ triliun (http://nasional.kompas.com). Secara keseluruhan, sejak 2004 hingga 2017, data statistik KPK menyebutkan, ada 616 kasus korupsi berdasarkan profesi jabatan yang didalamnya terdapat 88 Kepala Daerah yang berurusan dengan KPK. Diantaranya, 18 orang Gubernur dan 69 orang Wali Kota atau bupati dan wakilnya. (https://acch.kpk.go.id)

Memahami faktor-faktor yang dapat mempengaruhi minat pegawai untuk melakukan tindakan whistle-blowing penting dilakukan agar organisasi dapat melakukan kebijakan dan system whistle-blowing yang paling efektif. Berdasarkan Teory Of Planned Behaviour (TPB) yang dikemukakan oleh Anjzen (1991) yang berusaha menghubungkan sikap dengan perilaku. TPB membuktikan bahwa minat lebih akurat dalam memprediksi perilaku aktual dan sekaligus dapat menghubungkan antara sikapdanperilaku aktual. TPB memiliki tiga determinan yang saling independen diantaranya sikap terhadap perilaku, faktor sosial dan persepsi kontrol. Dalam TPB menjelaskan hubungan antara ketiga determinan tersebut yang sangat berpengaruh terhadap minat. Dalam penelitian ini perilaku yang akan diteliti adalah whistle-blowing. Peneliti ingin meneliti apakah sikap terhadap perilaku dan faktor sosial (faktor personal cost) dapat mempengaruhi minat melakukan tindakan whistle-blowing.

Beberapa penelitian memberikan hasil yang tidak konsisten mengenai pengaplikasian Theory of Planned Behavior, penelitian tersebut diantaranya dilakukan oleh Uddin dan Gillet (2005) yang memberikan hasil norma subyektif berpengaruh negatif pada niat manajer keuangan dalam melakukan kecurangan penyajian laporan keuangan. Hasil penelitian berbeda didapatkan oleh Carpenter dan Reimers (2005) yang menunjukkan bukti empiris norma subyektif berpengaruh positif pada niat manajer keuangan dalam melakukan kecurangan penyajian laporan keuangan. Penelitian Banda (2012) yang menguji TPB terhadap niat whistleblowing pada internal auditor BPK menemukan bahwa penalaran moral dan persepsi kendali atas perilaku berpengaruh tidak signifikan terhadapintensi untuk melakukan pengungkapan kecurangan, sedangkan sikap kearah perilaku dan norma subjektif berpengaruh terhadap niat whistle-blowing.

Penelitian ini dilakukan untuk menguji lima determinan yaitu sikap terhadap whustleblowing, komitmen organisasi, personal cost, keseriusan kecurangan, dan tekanan ketaatan dalam mempengaruhi minat pengelola keuangan Universitas Bengkulu melakukan whistleblowing. Penggunaan responden yang berasal dari lingkungan Universitas Bengkulu diharapkan dapat memperkaya hasil penelitian sejenis di sektor publik di Indonesia yang merupakan negara berkembang dengan karakteristik tingkat korupsinya yang masih tinggi. 
Dalam penelitian ini peneliti menggunakan dua contoh kasus berbeda yang digunakan sebagai tolak ukur dalam indikator dalam kuisioner yang akan di sebar. Hal ini dilakukan agar peneliti dapat melihat adakah perbedaan yang didapat terhadap hasil penelitian terkait masing-masing kasus yang dihadapi.

\section{KERANGKA TEORITIS DAN HIPOTESIS}

\section{Teori Perilaku Terencana (Theory Of Planned Behaviour)}

Theory of Planned Behaviour (TPB) adalah teori psikologi yang dikemukakan oleh Icek Ajzen (1991) yang berusaha menjelaskan hubungan antara sikap dengan perilaku. Theory of Planned Behaviour TPB muncul sebagai jawaban atas kegagalan determinan sikap (attitude) dalam memprediksi tindakan/perilaku aktual (actual behavior) secara langsung. TPB membuktikan bahwa minat (intention) lebih akurat dalam memprediksi perilaku aktual dan sekaligus dapat sebagai proxy yang menghubungkan antara sikap dan perilaku aktual. Menurut Ajzen (1991), minat diasumsikan untuk menangkap faktor motivasi yang mempengaruhi sebuah perilaku, yang ditunjukkan oleh seberapa keras usaha yang direncanakan seorang individu untuk mencoba melakukan perilaku tersebut.

\section{Prosocial Organizatinal Behavior Theory}

Prosocial behaviour merupakan kategori yang luas dari helping behavior. Prosocial behavior didefinisikan oleh beberapa segmen yang signifikan dari masyarakat atau kelompok sosial yang secara umum dapat menguntungkan bagi orang lain. Brief (1986) mendefinisikan prosocial organizational behavior sebagai perilaku/tindakan yang dilakukan oleh anggota sebuah organisasi terhadap individu, kelompok, atau organisasi yang ditujukan untuk meningkatkan kesejahteraan individu, kelompok, atau organisasi tersebut.

\section{Whistle-blowing}

Whistle-blowing atau dapat diartikan sebagai pengungkapan rahasia, merupakan suatu tindakan mengungkapkan suatu kecurangan atau perilaku tidak etis dalam suatu organisasi kepada pihak yang berwewenang baik itu pihak dalam organisasi itu sendiri atau kepada pihak diluar organisasi dan dilakukan oleh pegawai atau mantan pegawai organisasi itu sendiri. Vinten (2000) dalam Malik (2010) mendefinisikan whistle-blowing sebagai suatu pengungkapan oleh karyawan mengani suatu informasi yang diyakini mengandung pelanggaran hukum, peraturan, pedoman praktis atau pernyataan profesional, atau berkaitan dengan kesalahan prosedur, korupsi, penyalahgunaan wewenang, atau membahayakan publik dan keselamatan tempat kerja. Ada banyak penelitian yang telah dilakukan guna mencari faktor-faktor yang mempengaruhi seseorang untuk melakukan whistle-blowing dengan menggunakan minat whistle-blowing sebagai pengukurnya. Minat whistle-blowing berbeda dengan tindakan whistle-blowing aktual karena minat muncul sebelum tindakan whistleblowing aktual, atau dapat dikatakan perlu adanya minat whistle-blowing untuk membuat tindakan whistle-blowing aktual terjadi (Winardi, 2013). 
FAKTOR - FAKTOR YANG MEMPENGARUHI...

Dewi Sutrisni dan Isma Coryanata

Faktor-faktor yang mempengaruhi whistle-blowing

\section{Sikap Terhadap Whistle-blowing}

Sikap adalah perasaan, pikiran, dan kecenderungan seseorang yang kurang lebih bersifat permanen mengenal aspek-aspek tertentu dalam lingkungannya. Menurut Park dan Blenkinsopp (2009) mendefinisikan sikap sebagai penilaian seorang individu atas seberapa setuju atau tidak setujunya individu tersebut terhadap suatu perilaku/tindakan tertentu. Menurut Theory of Planned Behavior (TPB), sikap adalah salah satu variabel yang mempengaruhi minat perilaku seseorang.

Penelitian terdahulu menemukan bahwa sikap terhadap whistle-blowing memang berpengaruh terhadap minat whistle-blowing Park dan Blenkinsopp (2009) dalam penelitiannya Whistleblowing as Planned Behaviour, Winardi (2013) yang meneliti minat Pegawai Negeri Sipil tingkat rendah. Penelitian Kusuma dan Wuryan (2015) juga menjelaskan bahwa sikap terhadap whistle-blowing berpengaruh positif terhadap minat melakukan tindakan whistlblowing pada PNS BPKP Jawa Timur di Surabaya dan diperkuat oleh Bagustiono dan Nurkholis (2015) yang meneliti PNS BPK RI juga menjelaskan bahwa sikap terhadap whistleblowing berpengaruh positif terhadap minat melakukan tindakan whistle-blowing. Berdasarkan penjelasan di atas dan hasil-hasil penelitian sebelumnya, hipotesis pertama yang diajukan dalam penelitian ini ialah:

H1: a). Pada kasus pemotongan insentif karyawan Sikap terhadap whistle-blowing berpengaruh positif terhadap minat pengelola keuangan melakukan tindakan whistle-blowing.

b). Pada kasus SPJ Fiktif Sikap terhadap whistle-blowing berpengaruh positif terhadap minat pengelola keuangan melakukan tindakan whistle-blowing.

\section{Komitmen Organisasi}

Komitmen organisasi merupakan sikap yang mencerminkan sejauh mana seseorang individu atau pegawai mengenal dan terikat pada organisasinya (Griffin, 2004). Menutur Robbins (2007) komitmen adalah suatu keadaan dimana seorang pegawai memihak kepada sesuatu organisasi tertentu dan tujuan-tujuannya serta berniat memelihara keanggotaan dalam organisasi itu. Mathis dan Jackson dalam (Sopiah, 13 2008) menyatakan komitmen organisasi sebagai keadaan dimana karyawan percaya dan mau menerima tujuan-tujuan organisasi dan akan tetap tinggal atau tidak akan meninggalkan organisasinya. Allen (1996) mengemukakan tiga komponen model komitmen terhadap organisasi, mengenal dan terikat pada organisasinya (Griffin, 2004).

Penelitian yang dilakukan oleh Somers (1994) yang menjelaskan bahwa komitmen organisasi mempengaruhi whistle-blowing. Dalam penelitian yang dilakukan Kusuma dan Wuryan (2015) diperoleh hasil bahwa komitmen organisasi berpengaruh signifikan terhadap PNS BPKP Jawa Timur dalam melakukan tindakan whistle-blowing. Sejalan dengan penelitian sebelumnya penelitian Bagustiono dan Nurkholis (2015) juga menyimpulkan bahwa komitmen organisasi berpengaruh terhadap minat whistle-blowing pada PNS BPK RI. Pada penelitian tersebut responden yang diklasifikasikan dalam tingkatan berkomitmen organisasi moderat memiliki kecenderungan untuk melaporkan kecurangan paling tinggi dibandingkan yang memiliki komitmen organisasi rendah ataupun tinggi. Berdasarkan penjelasan di atas dan hasilhasil penelitian sebelumnya, hipotesis ke dua yang diajukan ialah:

H2: a). Pada kasus pemotongan insentif karyawan Komitmen organisasi berpengaruh positif terhadap minat pengelola keuangan melakukan tindakan whistle-blowing.

b). Pada kasus SPJ Fiktif Komitmen organisasi berpengaruh positif terhadap minat pengelola keuangan melakukan tindakan whistle-blowing. 


\section{Personal Cost}

Personal cost of reporting adalah pendapat pegawai terhadap risiko pembalasan/balas dendam atau sanksi dari anggota organisasi, yang dapat mengurangi minat pegawai untuk melaporkan kecurangan (Schutlz et al., 1993). Anggota organisasi yang dimaksud dapat saja berasal dari manajemen, atasan, atau rekan kerja. Tindakan balasan yang didapat diantaranya langkah-langkah yang diambil organisasi untuk melemahkan proses pengaduan, isolasi whistleblower, pencemaran karakter dan nama baik, mempersulit atau mempermalukan whistleblower, pengecualian dalam rapat, penghapusan penghasilan tambahan, dan bentuk diskriminasi atau gangguan lainnya (Parmerlee,1982). Pembalasan lainnya yang dapat terjadi dalam bentuk tidak berwujud (intangible), misalnya penilaian kinerja yang tidak seimbang, hambatan kenaikan gaji, pemutusan kontrak kerja, atau dipindahkan ke posisi yang tidak diinginkan (Curtis, 2006). Sabang (2013) juga menambahkan bahwa personal cost bukan hanya dampak tindakan balas dendam dari pelaku kecurangan, melainkan juga keputusan menjadi pelapor dianggap sebagai tindakan tidak etis, misalnya melaporkan kecurangan atasan dianggap sebagai tindakan menentang atasan. Bukan hanya itu saja bahkan dapat membahayakan keluarga yang lainnya jika yang dilaporkan tersebut memiliki sikap pemndendam yang tinggi dan juga memiliki tempramen yang tidak baik.

Beberapa penelitian yang dilakukan membuktikan bahwa personal cost tidak berpengaruh diantaranya penelitian yang dilakukan oleh Magnus (2005) menunjukkan bahwa ancaman pembalasan memiliki hubungan/korelasi negatif dengan minat untuk melakukan whistle-blowing. penelitian Winardi (2013) juga menyimpulkan bahwa ternyata variabel personal cost of reporting tidak mampu menjadi faktor yang menjelaskan minat whistleblowing pada pegawai negeri tingkat bawah. Begitu juga penelitian yang dilakukan oleh Bagustiono dan Nurkholis (2015) yang menjelaskan bahwa personal cost tidak berpegaruh terhadap minat PNS BPK RI untuk melakukan tindakan whistle-blowing.

Berdasarkan penjelasan di atas dan hasil-hasil penelitian sebelumnya, hipotesis ke tiga yang diajukan ialah:

H3: a). Pada kasus pemotongan insentif karyawan Personal Cost berpengaruh negatif terhadap minat pengelola keuangan melakukan tindakan whistle-blowing.

b). Pada kasus SPJ Fiktif Personal Cost berpengaruh negatif terhadap minat pengelola keuangan melakukan tindakan whistle-blowing.

\section{Tingkat Keseriusan Kecurangan}

Yang dimaksud dengan tingkat keseriusan kecurangan adalah ukuran seberapa besar keseriusan kecurangan yang dapat merugikan organisasi Anggota organisasi yang mengamati adanya dugaan kecurangan akan lebih mungkin untuk melakukan whistle-blowing jika kecurangan tersebut serius Miceli et al., (1985). Organisasi akan terkena dampak kerugian yang lebih besar dari kecurangan yang lebih serius dibandingkan dari kecurangan yang kurang serius (Winardi, 2013).

Penelitin Bagustiono dan Nurkholis (2015) juga menjelaskan bahwa komitmen organisasi berpengaruh positif terhadap minat PNS melakukan tindakan whistle-blowing. Hasil ini sejalan dengan konsep Prosocial Organizational Behavior dan konsep komitmen organisasi yaitu bahwa tindakan whistle-blowing merupakan perilaku sosial positif yang dapat memberikan manfaat bagi organisasi dalam bentuk melindungi organisasi dari bahaya kecurangan (fraud). Diperkuat dengan penelitian Aliyah (2015) juga menjelaskan bahwa menyatakan bahwa komitmen organisasi berpengaruh positif terhadap minat pegawai pegawai tetap UNISNU Jepara untuk melakukan tindakan whistle-blowing. Penelitian-penelitian tersebut menjelaskan bahwa tingkat keseriusan kecurangan berpengaruh terhadap minat 
FAKTOR - FAKTOR YANG MEMPENGARUHI...

Dewi Sutrisni dan Isma Coryanata

melakukan tindakan whistle-blowing. Berdasarkan penjelasan di atas dan hasil-hasil penelitian sebelumnya, hipotesis terakhir yang diajukan ialah:

H4: a). Pada kasus pemotongan insentif karyawan Tingkat keseriusan kecurangan berpengaruh positif terhadap minat pengelola keuangan untuk melakukan tindakan whistle-blowing.

b). Pada kasus SPJ Fiktif Tingkat keseriusan kecurangan berpengaruh positif terhadap minat pengelola keuangan untuk melakukan tindakan whistle-blowing.

\section{Tekanan ketaatan}

Teori ketaatan menyatakan bahwa individu yang memiliki kekuasaan merupakan suatu sumber yang dapat mempengaruhi perilaku orang dengan perintah yang diberikannya, hal ini disebabkan oleh keberadaan kekuasaan atau otoritas yang merupakan bentuk (Jamilah et al., 2007). Dalam beberapa situasi sosial, seseorang sebagai pemilik kekuasaan yang sah dipandang dapat mempengaruhi perilaku orang tersebut. Norma sosial membolehkan pihak yang memiliki kekuasaan yang sah untuk mengajukan permintaan dan memaksa agar bawahan mematuhinya. Bahkan orang yang dalam kehidupan sehari - harinya merupakan seseorang yang bertanggung jawab dan terhormat bisa jadi tertekan oleh otoritas dan mau saja melakukan tindakan kejam dalam situasi tertekan.

Hasil penelitian Cahyaningrum (2015) dengan melakukan eksperimen pada mahasiswa pengauditan menemukan bahwa tekanan ketaatan berpengaruh terhadap yang dibuat oleh auditor junior. Jamilah et al., (2007) melakukan survey terhadap auditor yang bekerja pada Kantor Akuntan Publik di Jawa Timur mengemukakan bahwa tekanan ketaatan berpengaruh secara signifikan terhadap keputusan audit. Diperkuat dengan penelitian Widi dan Utami (2015) yang menggunakan sampel mahasiswa Fakultas Ekonomika dan Bisnis Universitas Kristen Satya Wacana disebutkan bahwa Semakin tinggi tekanan ketaatan yang dirasakan oleh whistle-blower maka akan memicu whistle-blower untuk tidak melakukan tindakan whistleblowing.

Berdasarkan penjelasan di atas dan hasil-hasil penelitian sebelumnya, hipotesis terakhir yang diajukan ialah:

H5: a). Pada kasus pemotongan insentif karyawan Tekanan Ketaatan berpengaruh positif terhadap minat pengelola keuangan melakukan tindakan whistle-blowing.

b). Pada kasus SPJ Fiktif Tekanan Ketaatan berpengaruh positif terhadap minat pengelola keuangan melakukan tindakan whistle-blowing.

Dari hipotesis diatas dapat dijelaskan dengan kerangka penelitian di bawah ini:

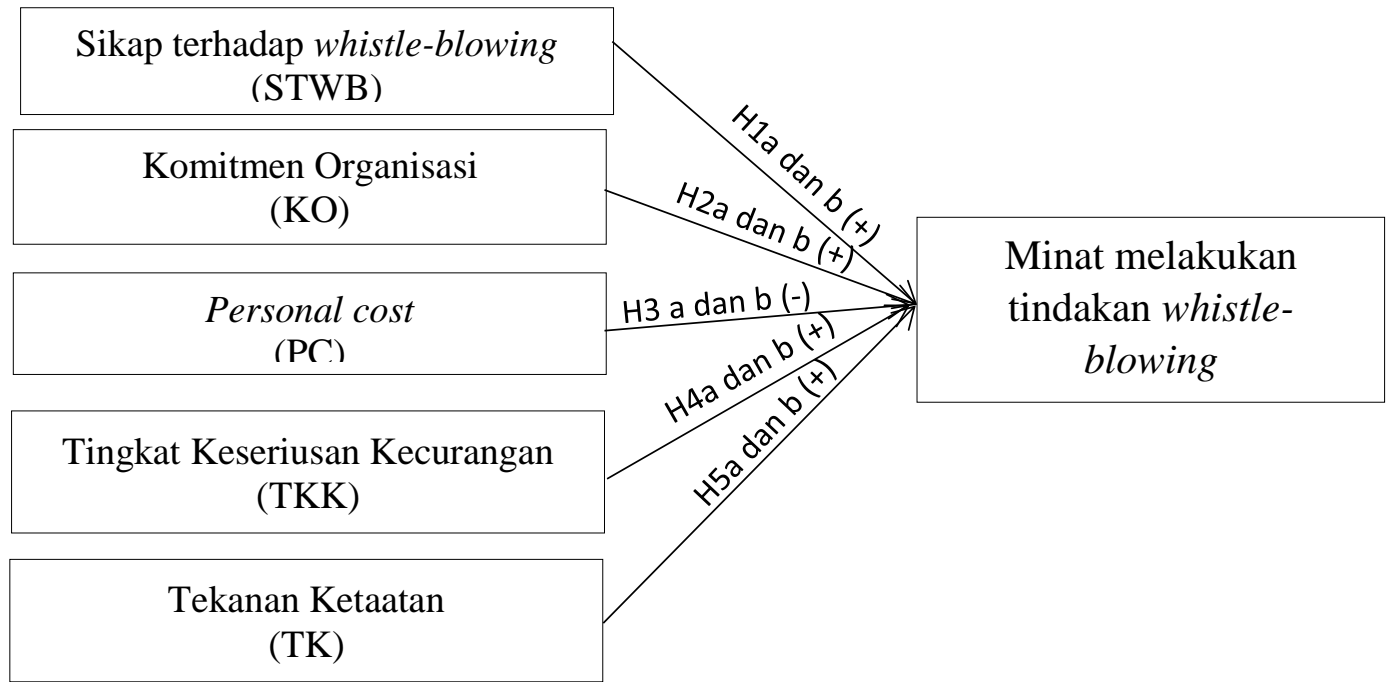

Gambar 1 Kerangka Penelitian 


\section{METODE PENELITIAN}

\section{Populasi dan Sampel}

Populasi adalah jumlah keseluruhan objek yang yang karakteristiknya dapat diukur. Populasi merupakan wilayah generalisasi yang terdiri atas objek atau subjek yang mempunyai kualitas dan karakteristik tertentu yang ditetapkan oleh penelti untuk dipelajari dan kemudian ditarik kesimpulannya (Sugiyono, 2011). Populasi dalam penelitian ini adalah seluruh pegawai yang bekerja di semua unit di lingkungan Universitas Bengkulu.

\section{Metode Pengumpulan Data}

Data yang digunakan dalam penelitian ini merupakan data primer yang diperoleh langsung dari sumbernya. Data yang digunakan berupa opini dari subyek penelitian yang dikumpulkan dengan mengunakan metode survei yaitu melalui kuesioner. Kuesioner disebar sendiri oleh peneliti dengan mendatangi bagian pengelola keuangan unit-unit di Universitas Bengkulu dan diberi tenggang waktu selama seminggu paling lambat untuk pengembalian kuesioner tersebut.

\section{Desain kuisioner}

Peneliti menggunakan model pertanyaan yang telah ada dan digunakan pada penelitian terdahulu. Kuesioner yang digunakan akan mengukur satu variabel dependen dan empat variabel independen sesuai model penelitian yang telah ditetapkan. Namun peneliti telah memodifikasi kuisioner yang ada dengan menggunakan dua contoh kasus yang berbeda, kasus pertama mengenai pemotongan insentif karyawan dan kasus yang kedua menggunakan contoh kasus SPJ fiktif. Skala yang digunakan untuk pengukuran adalah skala likert yang dinyatakan dengan rentang angka 1 sampai dengan angka 5.

\section{Deskriptif Data}

\section{HASIL PENELITIAN DAN PEMBAHASAN}

Data penelitian ini dikumpulkan dengan menyebarkan secara langsung sebanyak 106 kuesioner kepada pengelola keuangan yang bekerja di 8 Unit Fakultas 4 Unit UPT, 3 Unit Lembaga dan pada Rektorat Universitas Bengkulu. Kuesioner disebarkan dengan cara mengantar langsung dengan responden. Jumlah kuesioner yang disebarkan sebanyak 106 kuesioner, dengan jumlah kuesioner yang kembali adalah 70 kuesioner, atau sebesar $66 \%$ tingkat pengembaliannya. Terdapat 8 kuesioner atau sebesar $8 \%$ yang tidak dapat digunakan dikarenakan banyak terjadi jawaban yang kosong. Jadi jumlah kuesioner yang digunakan sebagai data dalam penelitian ini berjumlah 62 kuesioner (atau 89\% dari jumlah kuesioner yang kembali, atau 58\% dari kuesioner yang disebarkan.

\section{Validitas Instrumen Penelitian}

Hasil pengujian validitas terhadap masing-masing variabel pada kasus 1 dan kasus 2 menghasilkan nilai Kaiser-Meyer-Olkin Measure of Sampling Adequacy (KMO MSA) sikap terhadap whistle-blowing 0,890 dan 0,839 (> 0.50), komitmen organisasi 0,678 dan 0,525 (> $0.50)$, personal cost 0,636 dan 0,852 (> 0.50), tingkat keseriusan kecurangan 0,746 dan 0,707 
FAKTOR - FAKTOR YANG MEMPENGARUHI...

Dewi Sutrisni dan Isma Coryanata

(>0.50), tekanan ketaatan 0,722 dan 0,804 (> 0.50) dan minat melakukan tindakan whistleblowing 0,764 dan 0,761 (>0.50).

\section{Hasil Pengujian Hipotesis}

Uji Hipotesis ini menggunakan model analisis regresi berganda, bertujuan untuk memprediksi seberapa besar kekuatan pengaruh variabel independen terhadap variabel dependen. Hasil uji hipotesis terdapat pada tabel berikut ini:

Tabel

Hasil Uji Regresi Kasus 1 dan Kasus 2

\begin{tabular}{|c|c|c|c|c|c|c|}
\hline \multirow[t]{2}{*}{ Variabel } & \multicolumn{3}{|c|}{ KASUS 1} & \multicolumn{3}{|c|}{ KASUS 2} \\
\hline & $\begin{array}{c}\text { Koef } \\
\text { Regresi }\end{array}$ & $\begin{array}{c}t \\
\text { hitung }\end{array}$ & Sig & $\begin{array}{c}\text { Koef } \\
\text { Regresi }\end{array}$ & t hitung & Sig \\
\hline $\begin{array}{l}\text { Sikap Terhadap Whistle-blowing } \\
\text { (STWB) }\end{array}$ & 0,449 & 3,647 & 0,001 & 0,693 & 9,911 & 0,000 \\
\hline Komitmen Organisasi (KO) & 0,052 & 0,688 & 0,494 & $-0,047$ & $-0,852$ & 0,398 \\
\hline Personal Cost (PC) & 0,115 & 0,802 & 0,426 & $-0,092$ & $-0,940$ & 0,351 \\
\hline $\begin{array}{l}\text { Tingkat Keseriusan Kecurangan } \\
\text { (TKK) }\end{array}$ & 0,052 & 0,353 & 0,726 & 0,269 & 1,699 & 0,095 \\
\hline Tekanan Ketaatan (TK) & 0,073 & 0,768 & 0,446 & 0,133 & 2,664 & 0,010 \\
\hline$R$ Square & \multicolumn{3}{|l|}{0,262} & \multicolumn{3}{|l|}{0,673} \\
\hline Adjust $R^{2}$ & \multicolumn{3}{|l|}{0,197} & \multicolumn{3}{|l|}{0,643} \\
\hline $\mathrm{F}$ & \multicolumn{3}{|l|}{3,986} & \multicolumn{3}{|l|}{23,018} \\
\hline Sig & \multicolumn{3}{|l|}{0,004} & \multicolumn{3}{|l|}{0,000} \\
\hline
\end{tabular}

Sumber: Data primer diolah, 2018

Uji F pada tabel 8 (kasus 1 dan kasus 2) di atas menyatakan masing-masing $\mathrm{F}=3,986$ dan 23,018 dengan nilai signifikan sebesar P value 0,004 dan 0,000 lebih kecil dari 0,05. Jadi dapat disimpulkan bahwa model penelitian yang digunakan pada kedua kasus diatas layak uji.

Nilai koefisien determinasi berganda Adjusted $R^{2}$ menunjukan seberapa besar variabel dependen dapat dijelaskan oleh variabel independen. Nilai adjusted $R^{2}$ dapat dilihat pada tabel 8 (kasus 1) yaitu sebesar 0,197 yang berarti bahwa minat pengelola keuangan melakukan whistle-blowing dipengaruhi oleh sikap terhadap whistle-blowing, komitmen organisasi, persocal cost, tingkat keseriusan kecurangan, tekanan ketaatan hanya sebesar 19,7\% sedangkan sisanya $80,3 \%$ dipengaruhi oleh faktor lain yang tidak diteliti. Namun berbeda dengan hasil uji adjusted $R^{2}$ pada tebel 8 (kasus 2) dengan nilai adjusted $R^{2}$ sebesar 0,643 yang berarti bahwa minat pengelola keuangan melakukan whistle-blowing dipengaruhi oleh sikap terhadap whistle-blowing, komitmen organisasi, persocal cost, tingkat keseriusan kecurangan, tekanan ketaatan hanya sebesar $64,3 \%$ dan sisanya $35,7 \%$ dipengaruhi oleh faktor lainnya yang tidak diuji dalam penelitian ini.

Hasi uji t menunjukkan bahwa pada kasus satu hanya sikap terhadap whistle-blowing yang memiliki $p$-value > 0,05 (0,001) secara statistik variabel sikap terhadap whistle-blowing signifikan sehungga dapat dikatakan bahwa hanya sikap terhadap whistle-blowing berpengaruh terhadap minat melakukan whistle-blowing sedangkan pada kasus dua terdapat dua variabel yang memiliki $p$-value > 0,05 (sikap terhadap whistle-blowing 0,000 dan tekanan ketaatan $0,010)$ sehingga pada kasus dua hanya dua variabel saja yang berpengaruh terhadap minat melakukan whistle-blowing.

\section{Pembahasan}

Hipotesis Pertama pada kasus 1 (H1a) menyatakan sikap terhadap whistle-blowing berpengaruh positif terhadap minat pengelola keuangan melakukan tindakan whistle-blowing. 
Berdasarkan hasil pengujian hipotesis secara statistik dengan menggunakan kasus pemotongan insentif karyawan menunjukkan bahwa sikap terhadap whistle-blowing berpengaruh positif terhadap minat pengelola keuangan Universitas Bengkulu melakukan tindakan whistle-blowing atau dengan kata lain hipotesis 1 (H1a) diterima.

Berdasarkan hasil pengujian hipotesis secara statistik dengan menggunakan kasus SPJ Fiktif menunjukkan bahwa sikap terhadap whistle-blowing berpengaruh positif terhadap minat pengelola keuangan Universitas Bengkulu melakukan tindakan whistle-blowing atau dengan kata lain hipotesis 1 pada kasus 2 (H1b) juga diterima.

Hipotesis kedua pada kasus pemotongan insentif karyawan (H2a) menyatakan bahwa komitmen organisasi berpengaruh positif terhadap minat pegawai melakukan tindakan whistleblowing. Berdasarkan hasil pengujian secara statistik menunjukkan bahwa dalam kasus 1 (pemotongan insentif) menunjukkan hasil yang tidak signifikan dengan kata lain hipotesis 2 pada kasus 1 (H2a) ditolak.

Dalam pengujian hipotesis ketiga pada kasus pemotongan insentif karyawan (H3a) yang berkaitan dengan pengaruh personal cost. Dari hasil pengujian pada kasus pemotongan insentif karyawan koefisien regresi menunjukkan arah yang positif, yang artinya semakin besar resiko yang dihadapi maka semakin tinggi minat melakukan tindakan whistle-blowing. Hal ini karena pada kasus pemotongan insentif karyawan tersebut berkaitan dengan individu karyawan itu sendiri, semakin besar pemotongan yang dilakukan maka akan semakin besar pula resiko yang akan dihadapi oleh pengelola keuangan. Semakin besar resiko yang dihadapi pengelola keuangan terhadap individu karyawan tersebut membuat semakin tinggi pula minat melakukan tindakan whistle-blowing. namun dari hasil pengujian yang menggunakan kasus 1 menunjukkan bahwa personal cost tidak berpengaruh terhadap minat pengelola keuangan Universitas Bengkulu melakukan tindakan whistle-blowing. Dengan kata lain hipotesis 3 pada kasus 1 (H3a) ditolak.

Hipotesis keempat pada kasus pemotongan insentif karyawan (H4a) menyatakan bahwa tingkat keseriusan kecurangan berpengaruh positif terhadap minat pengelola keuangan melakukan tindakan whistle-blowing. Berdasarkan hasil pengujian secara statistik dari kasus pemotongan insentif karyawan menunjukkan hasil yang tidak signifikan dengan nilai signifikan hal ini berarti bahwa pada kasus 1 hipotesis keempat (H4a) ditolak.

Hipotesis kelima pada kasus pemotongan insentif (H5a) yang menyatakan bahwa tekanan ketaatan berpengaruh positif terhadap minat pengelola keuangan melakukan tindakan whistle-blowing, pada kasus 1 menunjukkan hasil signifikasi hal ini berarti bahwa dalam kasus 1 hipoteis (H5a) ditolak. Hal ini dapat disimpulkan bahwa pada kasus pemotongan insentif tekanan ketaatan tidak dapat mempengaruhi minat pengelola keuangan melakukan tindakan whistle-blowing. Tekanan ketaatan bukanlah alasan pengelola keuangan melakukan pemotonga insentif karyawan, karena pemotongan insentif karyawan sendiri mungkin dilakukan untuk mensejahterakan karyawan yang lain.

\section{PENUTUP}

Berdasarkan hasil pengujian dan pembahasan terhadap data penelitian yang diperoleh dari responden yaitu pengelola keuangan yang bekerja di Universitas Bengkulu terkait dengan pengaruh sikap terhadap wistle-blowing, komitmen organisasi, personal cost, tingkat keseriusan kecurangan dan tekanan ketaatan terhadap minat melakukan tindakan whistle-blowing maka dapat disimpulkan bahwa:

1. Dari kedua kasus yang digunakan menunjukkan bahwa sikap terhadap wisthtle-blowing berpengaruh positif terhadap minat pengelola keuangan melakukan tindakan whistleblowing. ini berarti bahwa semakin baik sikap pengelola keuangan terhadap whistle- 
Dewi Sutrisni dan Isma Coryanata

blowing maka akan semakin berkeinginan untuk melakukan whistle-blowing jika terjadi kecurangan.

2. Dari kedua kasus yang digunakan menunjukkan bahwa komitmen organisasi tidak berpengaruh terhadap minat pengelola keuangan melakukan tindakan whistle-blowing. hal ini berarti bahwa komitmen organisasi tidak dapat dijadikan alasan untuk pengelola keuangan Universitas Bengkulu melakukan tindakan whistle-blowing

3. Dari kedua kasus yang digunakan menunjukkan personal cost tidak berpengaruh terhadap minat pengelola keuangan melakukan tindakan whistle-blowing. Hal ini berarti bahwa pengelola keuangan lebih banyak menghidari hal-hal yang memiliki resiko yang tinggi.

4. Dari kedua kasus yang digunakan menunjukkan tingkat keseriusan kecurangan tidak berpengaruh terhadap minat pengelola keuangan melakukan tindakan whistle-blowing. Hal ini berarti bahwa tingkat keseriusan kecurangan yang terjadi tidak membuat pengelola keuangan melakukan tindakan whistle-blowing.

5. Dalam variabel tekanan ketaatan terdapat hasil yang berbeda, dari kasus pemotongan insentif karyawan menunjukkan hasil bahwa tekanan ketaatan tidak berpengaruh terhadap minat pengelola keuangan melakukan tindakan whistle-blowing sedangkan pada kasus SPJ fiktif menunjukkan bahwa tekanan ketaatan berpengaruh positif terhadap minat pengelola keuangan melakukan tindakan whistle-blowing. Hal ini berarti bahwa tekanan ketaatan dapat mempengaruhi minat melakukan tindakan whistle-blowing berdasarkan dari kasus apa yang dihadapi.

Penelitian ini memeliki beberapa keterbatasan yang pertama, berkaitan dengan tema penelitian yang sensitif (berkaitan dengan whistle-blowing) dan pengukuran variabel. Pelaksanaan pengukuran yang tidak menghadapkan responden dengan kondisi nyata dikhawatirkan menyebabkan resonden menjawab pertanyaan survei secara normatif, sehingga hasil penelitian bisa saja menjadi bias dengan kondisi yang sebenarnya di lapangan. Kedua, penggunaan 2 contoh kasus yang berbeda pada kuisioner membuat kuisioner menjadi terlalu banyak pertanyaan sehingga membuat para responden menjawab tanpa membaca dengan jelas apa inti dari pertanyaan yang diberikan. Ketiga, keterbatasan waktu dan tenaga mengingat banyaknya responden yang sibuk.

\section{DAFTAR PUSTAKA}

Aliyah Siti, 2015. Analisis Faktor-Faktor Yang Mempengaruhi Minatpegawai Dalam Melakukan Tindakan Whistle-Blowing. Jurnal Ekonomi dan Bisnis Vol. 12 No. 2 Oktober 2015 Universitas Islam Nahdlatul Ulama (UNISNU) Jepara.

Ajzen, Icek. 1991. The Theory of Planned Behaviour. Organizational Behaviour and Human Decision Processes. Vol.50: 179-211.

Allen, N.J. and Meyer, J.P. 1996. Affective, Continuance, and Normative Commitment to the Organization: An Examination of Construct Validity. Vol 49, 252-276.

Azwar, S., 2011. "Sikap dan Perilaku. Dalam: Sikap Manusia Teori dan Pengukurannya”. 2nd ed. Yogyakarta: Pustaka Pelajar, 3-22.

Banda, F. L. 2012. Pengaruh Penalaran Moral, Sikap, Normatif Subyektif dan Persepsi Kontrol Perilaku terhadap Whistleblowing Intention. Tesis. Universitas Gadjah Mada.

Bagustianto, Rizki dan Nurkholis. 2015. Faktor-Faktor Yang Mempengaruhi Minat Pegawai Negeri Sipil (PNS) Untuk Melakukan Tindakan WhistleBlowing (Studi Pada PNS BPK RI). Simposium Nasional Akuntansi 18. 1619 September 2015. Medan.

Brief, Arthur P. dan Stephan J. Motowidlo. 1986. Prosocial Organizational Behaviours. Academy of Management Review. Vol. 11 (4); 710-725. 
Carpenter, Tina D., and Jane L. Reimers. 2005. Unethical and Fraudulent Financial Reporting: Applying the Theory of Planned Behavior. Journal of Business Ethics, Vol.60, pp: 115129.

Cahyaningrum, C. D. dan I. Utami. 2015. Apakah Tekanan Ketaatan dan Kompleksitas Tugas Berpengaruh Terhadap Keputusan Audit. Simposium Nasional Akuntansi XVIII, Medan, Indonesia.

Curtis, Mary B.. 2006. Are Audit-related Ethical Decisions Dependent upon Mood ?. Journal of Business Ethics. Vol.68; 191-209.

Diniatri, Ellysa. 2010. Korupsi, Whistleblowing dan Etika Organisasi. Skripsi. Malang: Jurusan Akuntansi, Fakultas Ekonomi Universitas Brawijaya.

Dozier, Janelle Brinker dan Miceli, Marcia P.. 1985. Potential Predictors of histle-Blowing: A Prosocial Behavior Perspective. Academy of Management Review. Vol. 10 (4); 823836. Vol. 10 (4); 823-836

Ghozali, Imam., 2016. Aplikasi Analisis Multivariate Dengan Program SPSS 23. Semarang: Badan Penerbit Universitas Diponegoro.

Griffin, 2004., Komitmen Organisasi, terjemahan, Jakarta : Erlangga

Indriantoro, Nur., dan Supomo, Bambang., 2014. "Metodologi Penelitian Bisnis Untuk Akuntansi \& Manajemen". Edisi Pertama. Yogyakarta : BPFE Yogyakarta.

Jamilah, S., Z. Fanani, dan G. Chandrarin., 2007. Pengaruh Gender, Tekanan Ketaatan dan kompletifitas tugas terhadap audit jugdment. Simposium Nasional Akuntansi X, Makassar, Indonesia.

Kasus Setya Novanto dalam http://nasional.kompas.com diakses pada tanggal 30 Desember 2017

Kasus Firman Azhari dalam http://bengkuluekspress.com/eks-bendahara-unib-ditangkap diakses tanggal 30 Desember 2017

Kasus korupsi di Indonesia, https://www.detik.com, diakses pada 29 Januari 2018

Keputusan Rektor Nomor 861/UN30/HK/2018 tentang Revisi ke III keputusan Rektor Universitas Bengkulu Nomor 461/UN30/HK/2018 tentang pengangkatan dan penetapan besaran honor pejabat perbendaharaan pengelola keuangan BLU pada unitunit kerja Di lingkungan Universitas Bengkulu tahun anggaran 2018.

Keputusan Rektor Nomor 745/UN30/HK/2018 tentang Revisi keputusan Rektor Universitas Bengkulu Nomor 07/UN30/HK/2018 tentang pengangkatan pejabat perbendaharaan pengelola keuangan BLU Universitas Bengkulu tahun anggaran 2018.

Khan, M.A. 2009. Auditors and Whistleblowing Law. April 2009, pp. 12-14.

Kuryanto, A. D. 2011. Pengaruh Independensi Auditor, Komitmen Organisasi, Gaya Kepemimpinan, dan Pemahaman Good Corporate Governance Terhadap Kinerja Auditor Eksternal (Studi pada Kantor Akuntan Publik di Indonesia). Tesis. Program Pasca Sarjana Fakultas Ekonomi dan Bisnis Universitas Brawijaya. Malang.

Laporan Tahunan laporan tahunan KPK tahun 2016

Lord, A. T. dan F. T. DeZoort., 2001. Theimpact and Moral Reasoning on Auditor's Responses to Social Influence Pressure. Accounting, organizations and society 26.

Malik M.G., Rahardian., 2010. Analisis Perbedaan Komitmen Profesional dan Sosialisasi Antisipatif Mahasiswa PPA dan Non-PPA Pada Hubungan DenganWhistleblowing (Studi Kasus Pada Mahasiswa Akuntansi Universitas Diponegoro). Skripsi. Semarang: Universitas Diponegoro.

Mathis, R.L. \& Jackson, J.H., 2003 Human Resource Managemen (10th ed.). interface Jakarta: Salemba Empat.

Menk, Karl Bryan., 2011. The Impact of Materiality, Personality Traits, and Ethical Position on Whistle-Blowing Intentions. Disertasi. Virginia: Program Doctor of Philosophy in Business, Virginia Commonwealth University. 
Merdikawati Risti dan Andri Prastiwi., 2012. Hubungan Komitmen Profesi dan Sosialisasi Antisipatif Mahasiswa Akuntansi Dengan Niat Whistleblowing. Jurnal akuntansi Universitas Diponegoro. Volume 1, Nomor 1, Tahun 2012, Halaman 1-10.

Magnus Mesmer, Jessica R. dan Viswesvaran, Chockalingam., 2005. Whistleblowing in Organizations: An Examination of Correlates of Whistleblowing Intentions, Actions, and Retaliation. Journal of Business Ethics. Vol. 52; 277-297.

Miceli, Marcia P. dan Near, Janet P., 1985. Characteristics of Organizational Climate and Perceived Wrongdoing Associated with Whistle-Blowing Decisions. Personnel Psychology. 1985 (38); 525-544.

Miceli, Marcia P., Near, Janet P., dan Schwenk, Charles R., 1991. Who Blows The Whistle and Why?. Industrial \& Labor Relation Review. Vol 45 (1); 113-130.

Mowday, R.T., Porter, L. W., \& Steers, R., (1982). Employee Organizational linkages: The psychology of commitment absenteeism, and turnover. San Diego, CA: Academic Press.

Mustapha, M and Ling Sing Siaw. 2012. Whistle Blowing :Perceptions of Future Accountants. International Conference on Economics Business Inovation, Vol. 38, pp. 135- 139

Ni Putu Ika Parianti, I Wayan Suwartana dan I Dewa Nyoman Badera., 2016. Faktor-Faktor Yang Mempengaruhi Niat dan Perilaku Whistle-blowing Mahasiswa Akuntansi. Jurnal Ekonomi dan Bisnis Universitas Udayana Vol 5.12 (2016): 4209-4236

Kusuma Nungki Astuti dan Wuryan Andayani., 2015. Analisis Faktor-Faktor yang Mempengaruhi Miat Pegawai Negeri Sipil (PNS) untuk Melakukan Tindakan Whistleblowing (Studi PNS pada BPKP Propinsi Jawa Timur di Surabaya). Jurnal Ekonomi dan Bisnis. Universitas Brawijaya

Park, Heungsik dan Blenkinsopp, John., 2009. Whistleblowing as Planned Behaviour - A Survey of South Korean Police Officer. Journal of Business Ethics. Vol. 85; 545-556.

Parmerlee, Marcia A., Near, Janet P., dan Jensen, Tamila C., 1982. Correlates of Whistleblowers Perceptions of Organizational Retaliation. Administrative Science Quarterly”. Vol. 27 (1); 17-34.

Robbins, Stephen P., dan Judge, Timothy A., 2007. Perilaku Organisasi Edisi 12. Jakarta: Salemba Empat.

Sabang, Muh. Iskandar., 2013. Kecurangan, Status Pelaku Kecurangan, Interaksi IndividuKelompok, dan Minat Menjadi Whistleblower (Eksperimen pada Auditor Internal Pemerintah. Tesis. Malang: Fakultas Ekonomi dan Bisnis Universitas Brawijaya.

Schultz-Jr., Joseph J., Johnson, Douglas A., Morris, Deigan dan Dyrnes, Sverre., 1993. An Investigation of The Reporting of Questionable Acts in an International Setting. Journal of Accounting Research. Vol. 31; 75-103.

Somers, Mark J. dan Casal, Jose C., 1994. Organizational Commitment and Whistle-Blowing: A Test of The Reformer and The Organization Man Hypotheses. Group \& Organization Management. Vol. 19 (3); 270-284.

Sopiah. 2008. Perilaku Organisasi, Andi, Yogyakarta.

Soeratno, dan Lincolin Arsyad. 2008. Metodologi Penelitian untuk Ekonomi dan Bisnis. Yogyakarta: UPP STIM YKPN.

Sugiyono., 2011. Metode Penelitian Pendidikan (pendekatan Kuantitatif, kualitatif dan R\&D)" Alfabeta, Bandung

Sugiyono. 2014. Metode Penelitian Kuantitatif, Kualitatif dan R\&D. Cetakan ke-21 Desember 2014. Bandung: CV Alfabeta.

Sulistomo, Akmal., 2012. Persepsi Mahasiswa Akuntansi Terhadap Pengungkapan Kecurangan. Skripsi Program Sarjana Akuntansi Universitas Diponegoro.

Sweeney, P., 2008. Hotlines Helpful for Blowing The Whistle. Financial Executive. Vol. 24 (4); 28-31. 
Transparency International. 2016. Corruption Perceptions Index 2016. (Online), (http://www.transparency.org/cpi2016/results, diakses 21 Agustus 2017).

Tindak pidana korupsi, Anti-Corroption Clearing House (ACCH) https://acch.kpk.go.id/id/statistik/tindak-pidana-korupsi, diakses pada 29 Januari 2018

Uddin, Nancy. and Peter. R. Gillet., 2005. CFO Intentions of Fraudulent Financial Reporting. Auditing: A Journal of Practice \& Theory, 24 (1), 55-75

Vinten., 2000, Whistleblowing towards disaster prevention and management.

Widi Libriani Eka dan Intiyas Utami., 2015. Studi Eksperimental Tekanan Ketaatan dan personal Cost : Dampaknya Terhadap Whistle-blowing Fakultas Ekonomika dan Bisnis Universitas Kristen Satya Wacana Salatiga. Vol. 15, No. 2

Winardi, Rijadh Djatu., 2013. The Influence of Individual and Situational Factors on LowerLevel Civil Servants' Whistle-Blowing Intention in Indonesia. Journal of Indonesian Economy and Business. Vol. 28 (3); 361-376.

Yani Fitri Jalil., 2014. Pengaruh Komitmen Profesional Dan Sosialisasi Antisipatif Mahasiswa Audit Terhadap Perilaku Whistleblowing. Jurnal Bisnis dan Manajemen Vol. 4, No. 2 Agustus 2014 Universitas Islam Negeri Syarif Hidayatullah Jakarta. 